\title{
Design and Experimental Validation of Voice Coil Motor for High Precision Applications
}

\author{
Mahesh S. Shewale \\ Dept.of Mechanical Engineering, \\ Purdue School of Engineering \& Technology, IUPUI, \\ Indianapolis,USA \\ mshewale@iupui.edu
}

\author{
Dr. Ali Razban \\ Dept.of Mechanical Engineering, \\ Purdue School of Engineering \& Technology, IUPUI, \\ Indianapolis,USA \\ arazban@iupui.edu
}

\author{
Dr. Suhas P. Deshmukh \\ Dept.of Mechanical Engineering, \\ Government College of Engineering, \\ Chandrapur,India \\ suhas.deshmukh@gmail.com
}

\author{
SharadS. Mulik \\ Dept.of Mechanical Engineering, \\ G. H. Raisoni College of Engineering \\ \& Management, Pune, India \\ sharadmulik@gmail.com
}

\author{
Hrishikesh B. Zambare \\ Dept.of Mechanical Engineering, \\ Purdue School of Engineering \& Technology, \\ IUPUI, \\ Indianapolis, USA \\ hzambare@umail.iu.edu
}

\begin{abstract}
Flexural structures are extensively beneficial when differentiated with conventional inflexible body structures where point accuracy positioning is strongly required extending in the range of microns. To fulfill clear and accurate positioning requirements, we come up with the solution of voice coil motors (VCM) with position estimator algorithm. Appropriate magnet and coil assembly is designed by considering the ultimate force for the application. Voice coil motor components are fabricated on milling machine and then assembled. This VCM is incorporated with dSPACE DS1104 R\&D controller with the help of linear current amplifier (LCAM) which controls VCM with respect to desired amplitude and frequency. Displacement of coil of VCM is detected with respect to fixed magnet by using linear variable differential transformer (LVDT) which generates analog voltage signal in relation with motion of coil. Static characteristic such as stiffness is determined using forcedeflection plot and dynamic characteristic like damping factor and frequency response are estimated with the help of transient response obtained by providing step input to the motor. Further, PID controller is implemented on this VCM and it is error observed is less than \pm 0.5 microns.
\end{abstract}

IndexTerms-voice coil, Finite Element Analysis, system identification, dSPACE DS1104, flexure

\section{INTRODUCTION}

In recent years where manpower is being substituted by highly perceptive robotic systems, usage of different forms of sensors \& actuators in these distinct arrangements for industrial utilization is an inevitable aspect [1]. Several actuators are utilized to work out the sequence of operations in the industrial processes. Types of motors like induction motors, stepper and servo motors are needed for rotary movement applications i.e. to facilitate movement in rotational direction[2-5]. AC or DC induction motors are used in case of rotation speed plays an important role for example in milling machines, lathe machines, etc. [6-8]. Stepper motors are applied where we need precise angular positioning of the shaft which is an important criterion to be considered. These motors possess high degrees of resolution ranging 10000 pulses per revolution which facilitate them in achieving accurate angular position. Servo motors are same as above mentioned excepting they facilitate a feedback signal with the help of sensor located on output shaft. This sensor can be used for measuring speed as well as angular position [9]. Therefore, many advanced techniques in rotary motors have been implemented till date $[10,11]$.

Besides, if linear motors are considered, several equipment are manufactured by using rotary motors. Many conventional structures are utilized for utilization of linear or translatory movement like lead screw, ball screw, hydraulic and pneumatic devices, etc. However, these mechanisms possess some disadvantages like friction, backlash and wear of elements involved in system $[1,9,12]$. Further, this equipment need lubrication and they have huge hysteresis. As far as mechanisms made of lead crews and ball screw are considered, their speed of operation is very low in linear motion which is a function of pitch. They have less efficiency and risk of leakages in hydraulic and pneumatic equipment is a serious condition to be taken care of [13-15]. Gear mechanisms like worm drive and rack $\&$ pinion are needed to be lubricated and pitting failure occurs after particular number of cycles [14-17].

To rectify these problems, we developed a new solution of voice coil actuators. Voice coil actuators are linear actuators which are utilized in speakers and headphones for conversion of electrical signals in proper vibrations and they generate sound waves. Besides, they are broadly used in motion head in hard disk drives that are utilized to store data in computers [18]. These are low load applications in which lesser actuation force is essential to be developed by voice coil motors. In industrial practices, huge forces are required to be generated $[19,20]$. To attain this, we are required to make appropriate corrections in the design of voice coil motor. This voice coil motor can be extensively applied in the fields where

This is the author's manuscript of the article published in final edited form as: 
preciseand accurate movement in the range of microns is irresistive aspect [21].

In this research work, an attempt has been made to discuss the design of voice coil actuator, its mechatronic integration and experimental validation. Section II mentions the working principle and design of voice coil motor. Section III describes the experimental setup required for the experimental investigation. Section IV discusses the development and implementation of PID control algorithm on the mechanism. Section V summarizes the results and outcomes are discussed. Section VI concludes the research paper in accordance with the objectives.

\section{Design of Voice CoIl Motor}

Voice coil actuators are direct motion, restricteddisplacementinstrumentswhichuse a permanent magnet and copper coil winding or conductor to develop a force that isequivalent to the current flowingthrough the conductor. These electromagnetic appliances are applied in linear and rotary movementfunctionswhich need single vector force output and tremendousacceleration or large frequency operation.

The governing principle of voice coil actuator is controlled by the principle of Lorentz Force. This rulestates that if a current carrying conductor is located in a magnetic field, a force will actupon the current carrying conductor. The magnitude of this force is given by:

\section{$F=k B L I N$} tesla,

Where $\mathrm{k}$ - motor constant, B - magnetic flux density in I - current flowing through the conductor in amperes, L length of the conductor in $\mathrm{m}, \mathrm{N}$ - number of conductors.

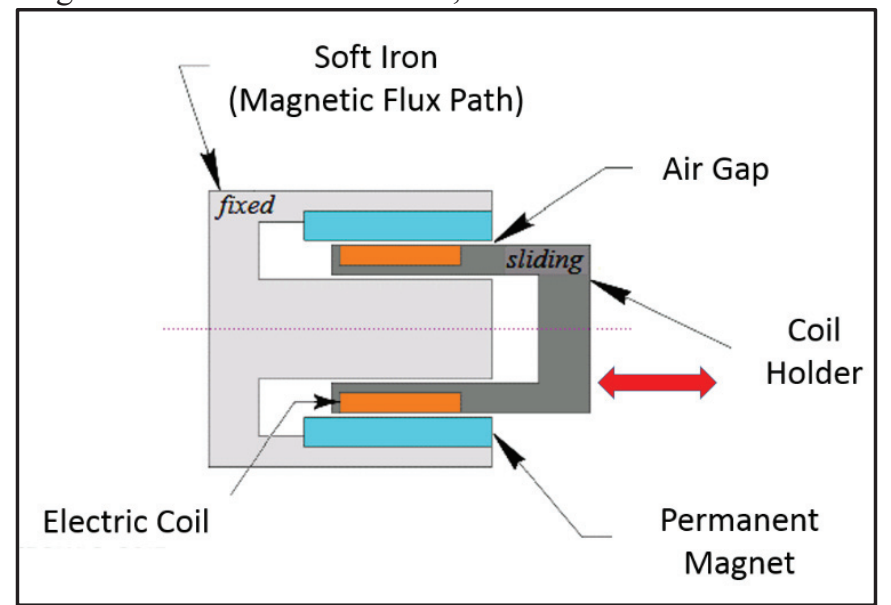

Fig. 1. Linear Voice Coil Actuator

In this case, the direction of the force developedrelies on the direction of current and magnetic field vectors. Especially, it is the cross-product of the two vectors. If polarity of flow of current is opposed, the directionof the force on the conductor is also opposed. If strength of magnetic field and length ofconductor are fixed, then resulting force is directly proportionateto input current.
In simplewords, a linear voicecoil motor is a cylindrical wire coil placed in a radially generated magnetic field, as shown in Figure 1. This field is developed by permanent magnets enclosedina ferromagnetic cylinder, arrangedso that the magnets "facing" the coil are of the same polarity. An inside core of ferromagnetic material isaligned along the central axis of the coil,joined at one end to the permanentmagnet assembly, is used to completethe magnetic circuit. The force developed axially on coil when currentflows through the coil generates a relative translatory motion in between the permanent magnet and the coil, added that the generated forceis huge enough to overcome friction,inertia, and any other forces from loadsattached to the coil.

As shown in Figure 2, the CAD model for voice coil actuator is developed with the help of ProECreo modelling software. Figure 2 elaborates the exploded view of voice coil motor assembly. At the initial stage, permanent magnet is kept in the aluminum housing block and it is attached to block by using alan screws. Copper wire is wound on a bobbin, one end which is enclosed in the magnet. The other end of cylindrical bobbin is attached to the output shaft with the help of coil holder. We utilize flexural bearing made of beryllium copper for maintaining the bobbin exactly at the center in axial as well as radial orientation. To constrain this flexural bearing to the housing block, we use a ring on which holes are made at its periphery for insertion of screws for fixing. Horizontal slots are provided at the expanded base of the housing to fix it to the optical table. Figure 4 shows the finally manufactured and assembled voice coil motor.

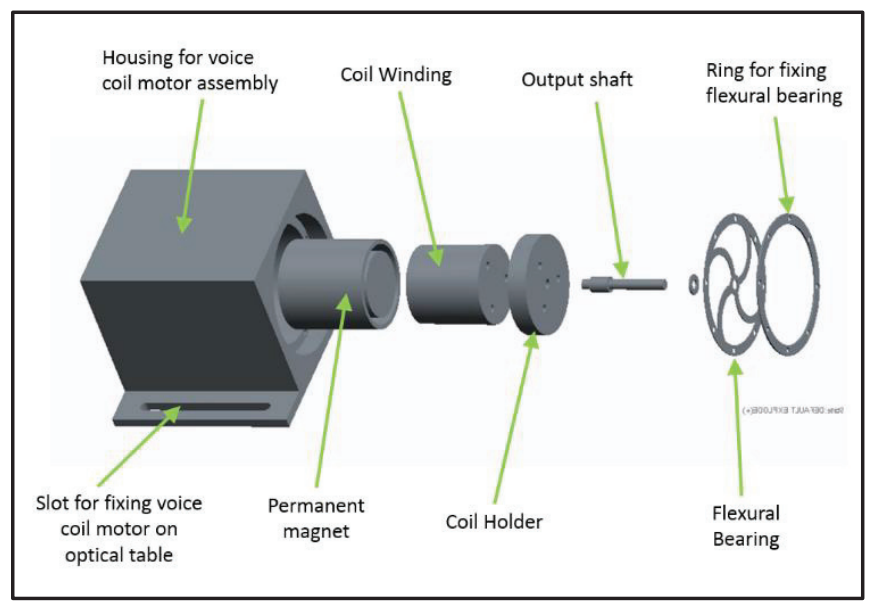

Fig. 2. Exploded view of voice coil motor assembly

FEA is a computerized technique for the prediction of behavior of a particular product to real world disturbances, vibrations, temperature changes, fluid flow and other physical quantities. It is anarithmeticaltechnique which is a division of solid mechanics and these dayscommonly used method to explain Multiphysics problems.

In our work, we use FEA software like ANSYS to estimate the variation of displacement of flexural bearing for various forces. Prepared CAD model is imported in ANSYS workbench and meshed to create small elements as shown in Figure 3(a).

The boundary constraints are applied on the outer 
periphery of flexural spring and force is applied in axial direction. The variation of deflection of flexural spring is noticed as shown in Figure 3(b) and stiffness is determined.

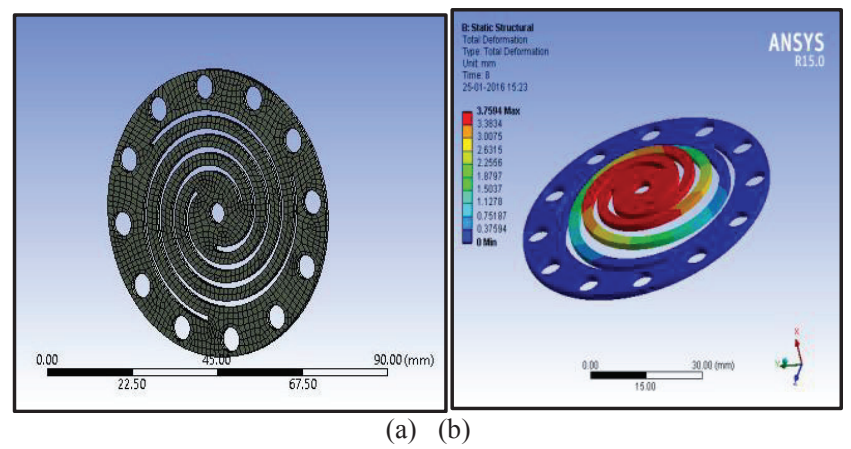

Fig. 3. Finite Element Analysis of Flexural Bearing

The Stiffness of spring is calculated by varying following parameters and the observations are recorded.

- Thickness of the Spring

- Spiral angle

- Width of cut

- Starting radius

- Ending radius

Stiffness is calculated for various combinations with the help of softwares (Catia and Ansys). We studied the trend of these parameters by changing them one by one while keeping others constant. Initially, we selected thickness of spring plate to be $0.5 \mathrm{~mm}, 1 \mathrm{~mm}, 1.25 \mathrm{~mm}$ and $1.5 \mathrm{~mm}$ based on the availability of material. Secondly selecting number of grooves as $2,3,4$. Third is by changing the spiral angles. Then fourth is by changing the width of cut. And lastly fifth by changing the inner and outer diameter of the groove.

For each changed value corresponding changes are made in the CAD design. This design is loaded into the geometric analysis of the ANSYS. All the material properties were loaded for beryllium copper. This material gives very high fatigue or cyclic loading resistance. Hence this material will last longer. Keeping this in mind this material was selected. After assigning the material and its properties, a mesh was generated on the structure. Then constraining of the fixed points was done by selecting various planes. Force (of $60 \mathrm{~N}$ ) was given in vertical direction of the plane of spring. Then after running the model, deflection was given by the software and by the formula Stiffness = Force/Deflection, Stiffness of each spring is calculated. Following are the trends obtained on the graphs as shown in figure 4 .
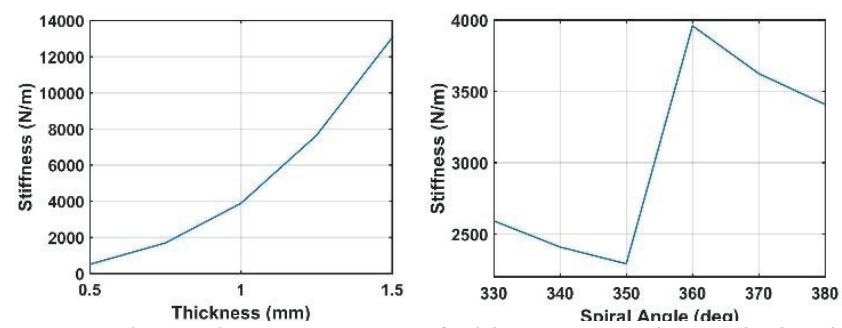

Based on the outcomes of this parametric optimization, appropriate values of parameters were selected that yields maximum deflection with minimum stresses. The voice coil motor was manufactured considering these values and integrated with LVDT to measure the movemet of output shaft as shown in Figure 5.
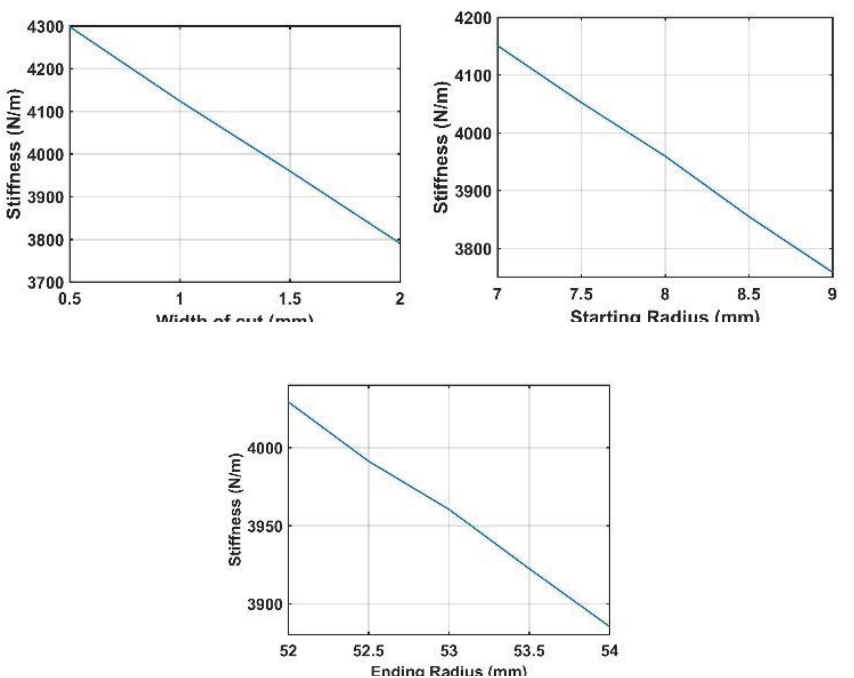

Fig. 4.Effect of various parameters in stiffness of flexural bearing

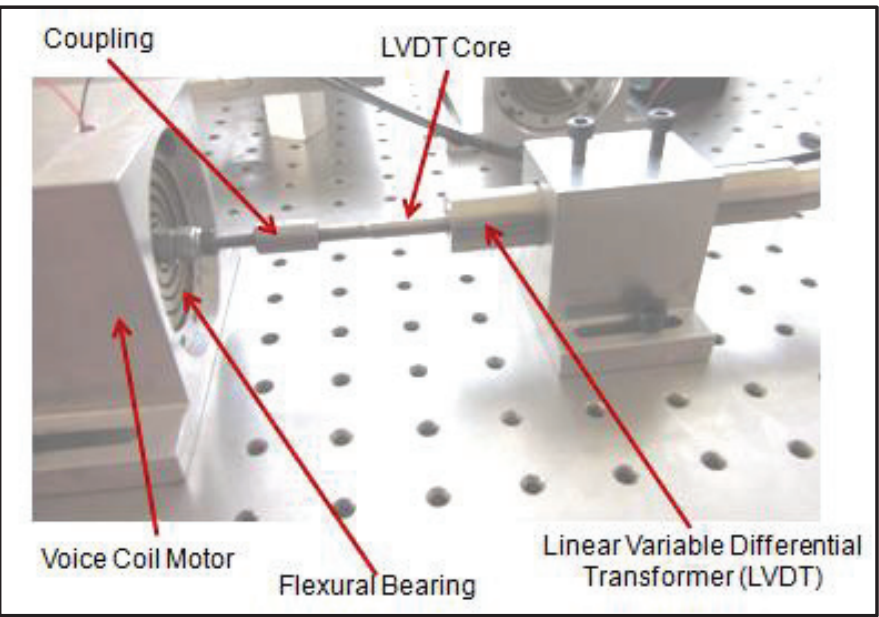

Fig. 5: Manufactured voice coil actuator

\section{MECHATRONIC INTEGRATION}

It is necessary for voice coil motor that it has to be run by using appropriate controller. We used dSPACE DS1104 R\&D controller to give desired amplitude and frequency of operation of voice coil actuation signal. When we give amplitude and frequency in ControlDesk GUI which is a frontend platform for dSPACE controller, the control logic developed in Simulink converts it into appropriate voltage signal which is forwarded to linear current amplifier (LCAM) through ADC port of CLP1104 connection board. This connection board provides connections for receiving and sending analog, digital, PWM and serial communication to the controller. The voltage signal from dSPACE is converted into current by using LCAM. It works as a driver circuit for 
voice coil motor. Output of VCM results in expected linear motion at the output shaft with regards to the desired amplitude and frequency. This movement is measured by using linear variable differential transformer (LVDT) having resolution in microns. Output of LVDT is a voltage that is equivalent to the movement of core of LVDT and this feedback voltage signal is provided to DAC port of dSPACE controller through CLP1104 connection board. This mechatronic integration is denoted in Figure 6 below.

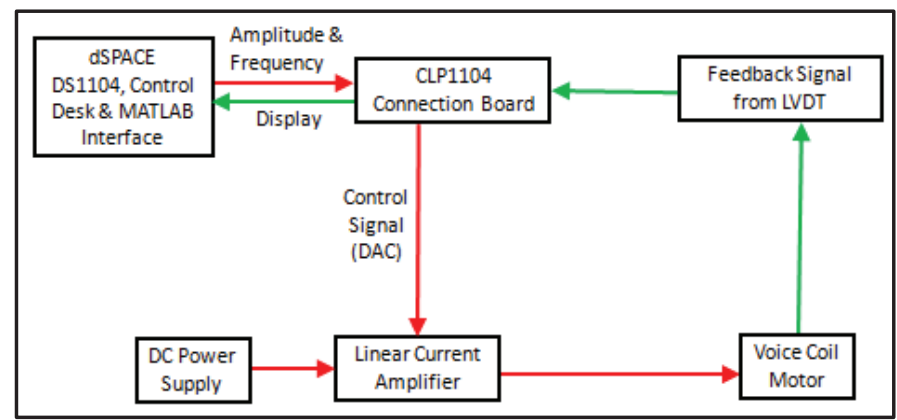

Fig. 6: Layout of Experimental Setup

\section{SYSTEM IDENTIFICATION}

Different parameters such as like stiffness, damping factor and so on can be assessed exactly by using flexural bearing in voice coil actuator integrated with dSPACE DS1104 R\&D controller. Natural frequency of the voice coil actuator is additionally determined for the set-up.

Stiffness Determination: Value of stiffness is determined for voice coil actuator assembly. MATLAB Simulink model was created to control the voice coil actuator and displacement of output shaft is measured by using LVDT having resolution in microns. Stiffness is practically determined in both forward and backward direction. Figure 7 demonstrates experimental force vs. deflection nature of output shaft of voice coil actuator.

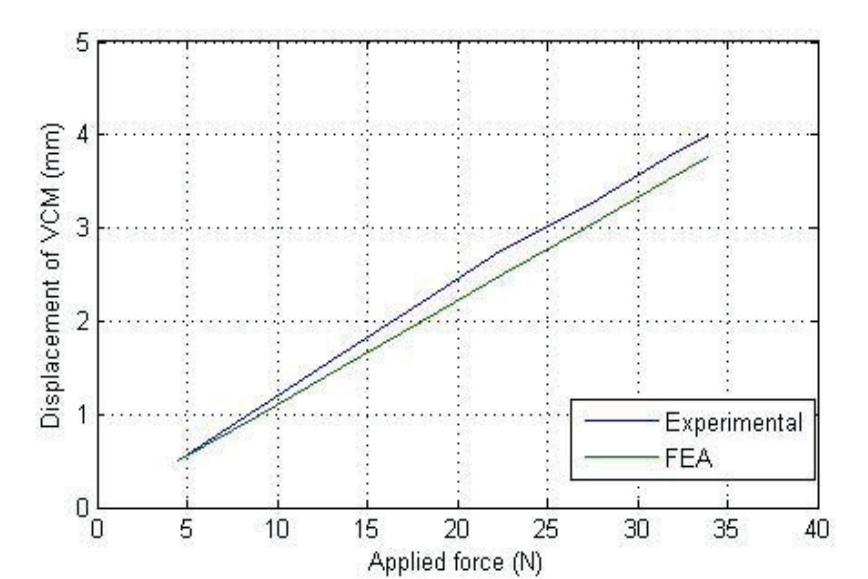

Fig. 7: Force deflection characteristics of VCM

Damping factor:Voice coil actuator is given an initial disturbance with the help of step input and then permitted to vibrate openly till it attains a steady state and comes to rest. Experimental observations (see Figure 8) are acquired and plotted as time vs deflection plot. Logic of logarithmic decrement is further utilized for the estimation of damping factor.

Logarithmic decrement is given by,

$$
\delta=\frac{1}{n}\left\lceil\log \frac{X_{0}}{X_{n}}\right\rfloor=0.06381
$$

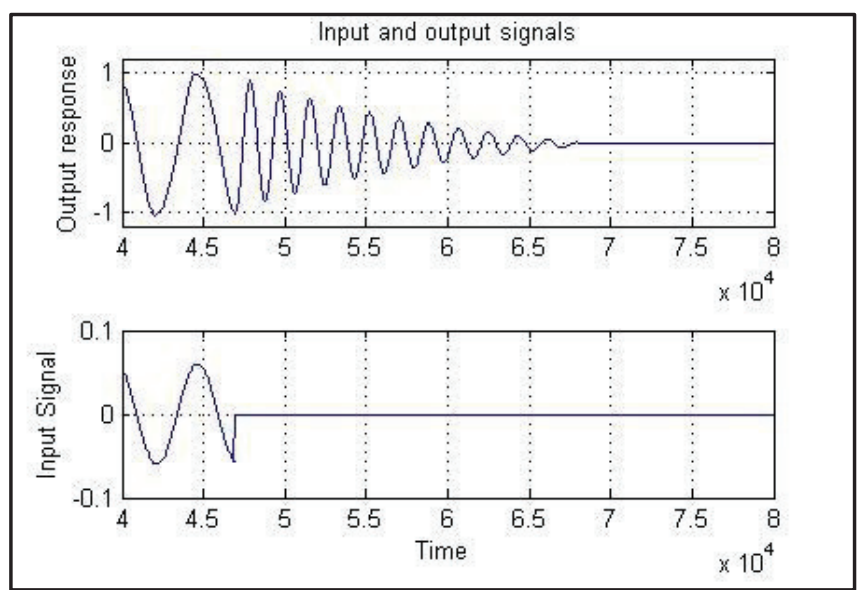

Fig. 8: Input step signal and output transient response

And damping factor is determined by

$$
\xi=\frac{\delta}{\sqrt{4 \pi^{2}-\delta^{2}}}=0.0102
$$

Frequency Response:

The experimental frequency response was determined form time domain data recorded as shown in Figure 9.

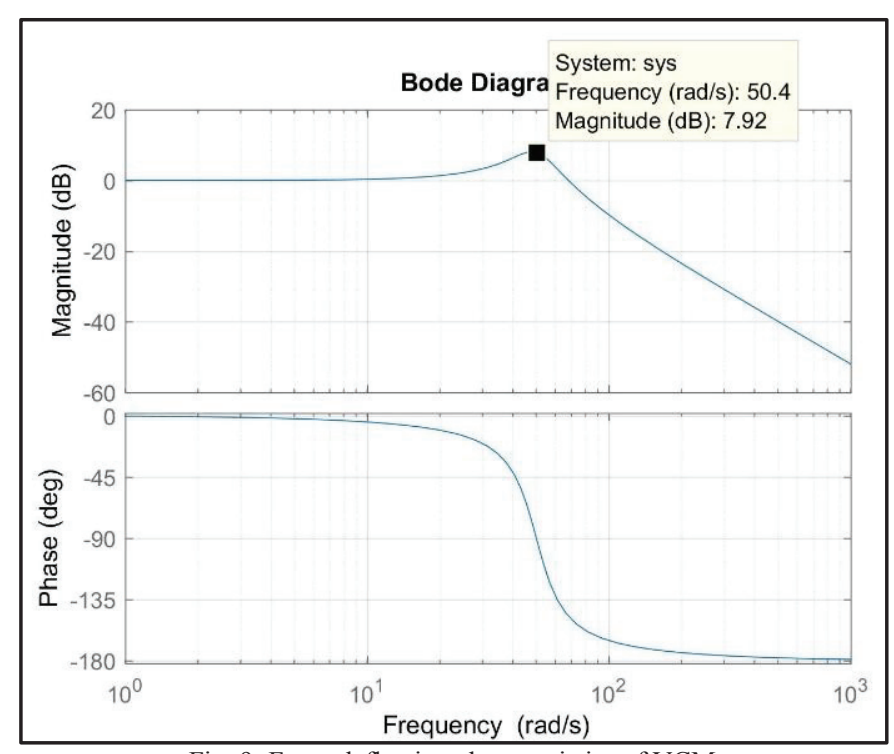

Fig. 9: Force deflection characteristics of VCM

Provided an amplitude of $1 \mathrm{~mm}$, a frequency response graph for the mechanism is developed to find out the natural frequency of the mechanism and the phase change tendency. Input signal provided was sinusoidal signal of amplitude 0.05 volts having $1-70 \mathrm{rad} / \mathrm{s}$ frequency range. The result we got 
was position estimation for every value of frequency. It is seen that peak value of frequency is $50.4 \mathrm{rad} / \mathrm{s}$, considered as an ultimate threshold value after which system is not stable.

From all the above information, we experimentally built up a transfer function as,

$$
G(s)=\frac{1}{s^{2}+0.1632 s+63.24}
$$

\section{DEVELOPMENT AND IMPLEMENTATION OF PID CONTROL ALGORITHM ON VCM}

A proportional-integral-derivative controller (PID controller)is a control loop feedback system (controller) broadlyutilized in practical control systems (see Figure 10). A PID controller determines an error value i.e. difference between a measuredprocess variable and a desired setpoint. The controller tries to minimize the error by adjusting the processthrough use of a manipulated variable.

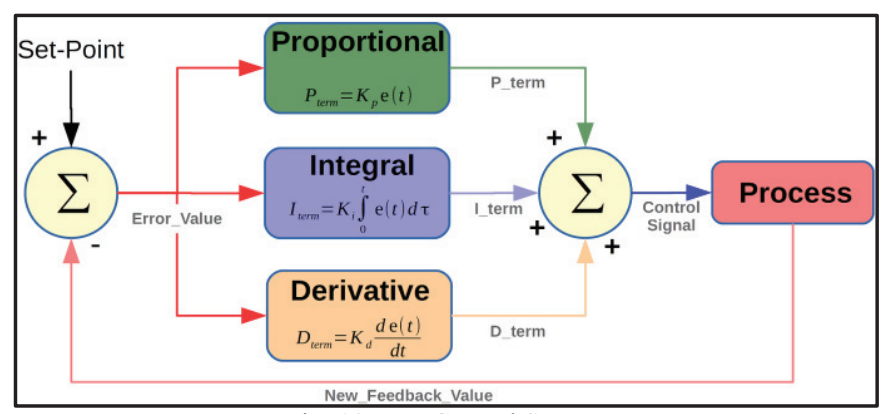

Fig. 10: PID Control System

The PID control algorithm includes three separate constantparameters, and is accordingly sometimes called three-termcontrol: the proportional, the integral and derivative values, denoted by $\mathrm{P}, \mathrm{I}$ and $\mathrm{D}$.

Figure 11 shows the Simulink block diagram for PID control implementation. A reference voltage signal is generated with the help of voltage generator logic. This reference signal is compared with the actual position signal generated by LVDT. This comparison produces error signal which is fed to the PID control block. Based on this error PID control logic tries to minimize it based on $\mathrm{K}_{\mathrm{P}}, \mathrm{K}_{\mathrm{I}}$ and $\mathrm{K}_{\mathrm{D}}$.

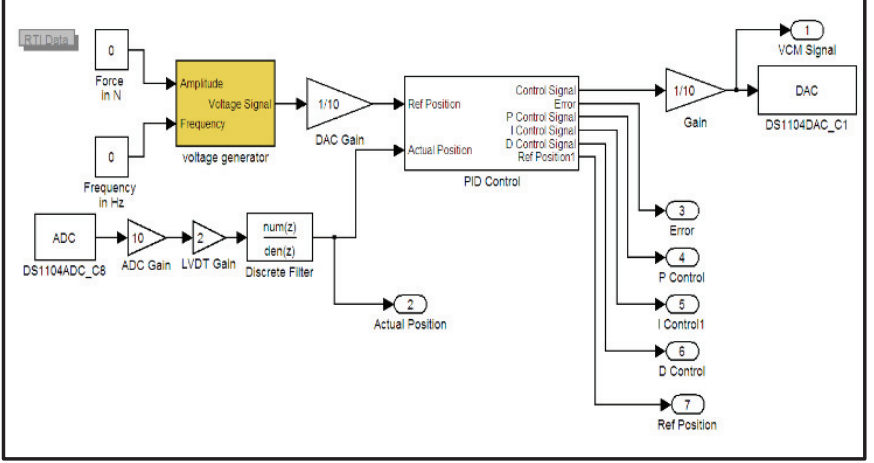

Fig. 11: Simulink model of PID Control Algorithm

\section{EXPERIMENTAL INVESTIGATION AND RESULTS}

Results are obtained for various amplitudes and frequencies as shown below in Figures 12 and 13.Figure 12 shows a Real time PID implementation results on DFM at lower speed $(0.75$ $\mathrm{Hz}$ Average Speed $=400 \mu \mathrm{m} / \mathrm{s}$ ) and small scan range (Amplitude $=100 \mu \mathrm{m}$ ) of motion stage.Position accuracy of less than $2.5 \mu \mathrm{m}$ is achieved. Figure 13 shows a Real time PID implementation results on DFM at lower speed $(0.75 \mathrm{~Hz}$ Average Speed $=2500 \mu \mathrm{m} / \mathrm{s}$ ) and small scan range (Amplitude $=7500 \mu \mathrm{m})$ of motion stage.

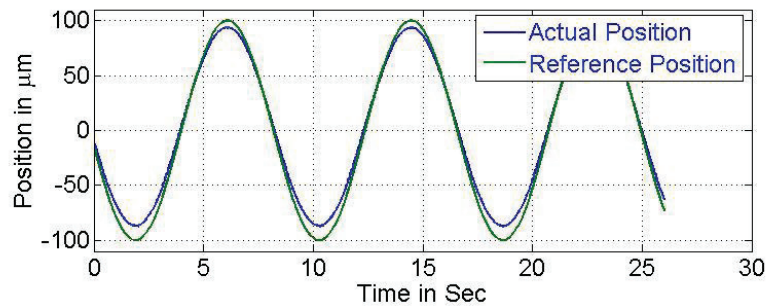

(a) Comparison between actual position and commanded reference position

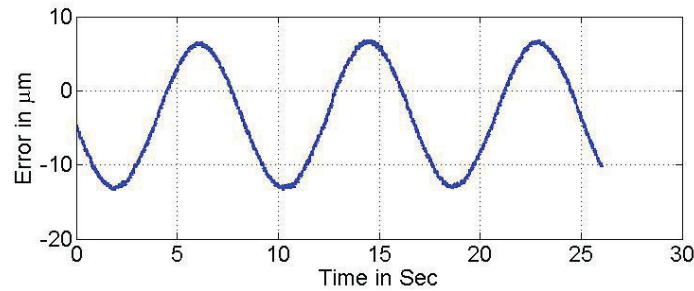

(b) Error in Real Time Precision Positioning

Fig. 12: Real Time PID Implementation on DFM at100 $\mu \mathrm{m}$ Amplitude and $0.75 \mathrm{~Hz}$ Frequency

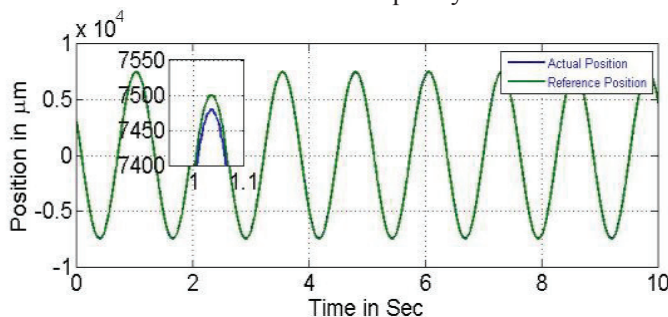

(a) Comparison between actual position and commanded reference position

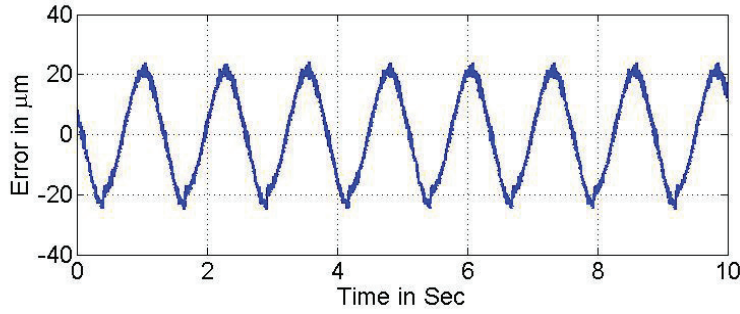

(b) Error in Real Time Precision Positioning

Fig. 13: Real Time PID Implementation on DFM at7500 $\mu \mathrm{m}$ Amplitude and $0.75 \mathrm{~Hz}$ Frequency

Position accuracy of about $20 \mu \mathrm{m}$ is achieved. The results achieved for variations in different amplitudes and frequencies are represented in Figure 14. 


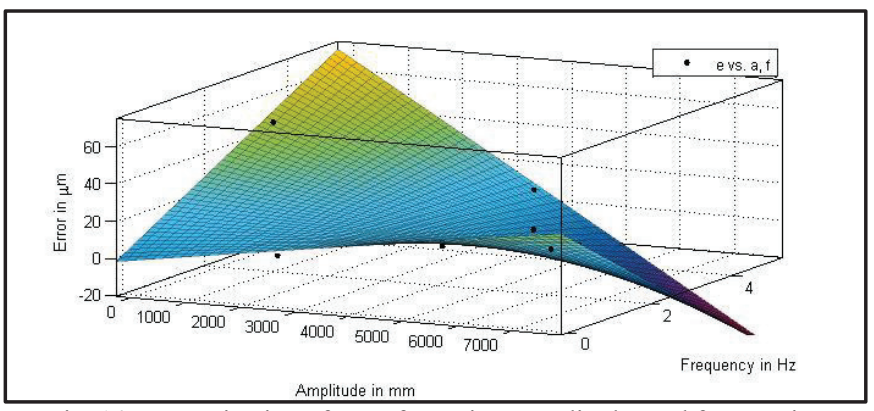

Fig. 14: Determination of error for various amplitudes and frequencies

\section{CONCLUSION}

Voice coil motor for high precision applications is successfully designed and fabricated. Further it is integrated with dSPACE DS1104 R\&D controller. PID Control algorithm is developed in MATLAB Simulink and it is applied on the voice coil motor. Static and dynamic characteristics such as stiffness, damping factor and frequency response are determined. PID parameters are tuned using Ziegler Nichols tuning method. Accuracy of less than 5 $\mu \mathrm{m}$ is achieved at low speeds and amplitude of $500 \mu \mathrm{m}$. Further as we increase the amplitude and frequency of operation, error increases at it is a progressive error. Voice coil motor involves smooth and frictionless motion that can be further applied to numerous micropositioning applications.

\section{REFERENCES}

[1] S. Awtar, "Synthesis and analysis of parallel Kinematic XY flexure mechanisms," Massachusetts Inst. Technol. Dept Mech. Eng., vol. 126, no. December 2003, p. 109, 2004.

[2] S. Awtar and A. Slocum, "A large range XY flexure stage for nanopositioning," Proc. 5th Euspen Int. Conf., no. May, pp. 491-494, 2005.

[3] S. Awtar, K. Shimotsu, and S. Sen, "Elastic Averaging in Flexure Mechanisms: A Three-Beam Parallelogram Flexure Case Study,” J. Mech. Robot., vol. 2, no. 4, pp. 41006-41012, 2010.

[4] S. Awtar and A. H. Slocum, "Constraint-Based Design of Parallel Kinematic XY Flexure Mechanisms," J. Mech. Des., vol. 129 , no. 8 , p. $816,2007$.

[5] C. Cheung and W. . Lee, "A theoretical and experimental investigation of surface roughness formation in ultra-precision diamond turning," Int. J. Mach. Tools Manuf., vol. 40, no. 7, pp. 979-1002, 2000.

[6] Y. M. Choi and D. G. Gweon, "A high-precision dual-servo stage using halbach linear active magnetic bearings," IEEE/ASME Trans. Mechatronics, vol. 16, no. 5, pp. 925-931, 2011.

[7] S. Ito and G. Schitter, "Comparison and classification of highprecision actuators based on stiffness influencing vibration isolation," IEEE/ASME Trans. Mechatronics, vol. 21, no. 2, pp. 1169-1178, 2016
[8] S. Ito, J. Steininger, and G. Schitter, "Low-stiffness dual stage actuator for long rage positioning with nanometer resolution," in Mechatronics, 2015, vol. 29, pp. 46-56.

[9] J. M. Huang, A. Q. Liu, Z. L. Deng, Q. X. Zhang, J. Ahn, and A. Asundi, "An approach to the coupling effect between torsion and bending for electrostatic torsional micromirrors," Sensors Actuators, A Phys., vol. 115, no. 1, pp. 159-167, 2004.

[10] J. Freire Gómez, J. D. Booker, and P. H. Mellor, "2D shape optimization of leaf-type crossed flexure pivot springs for minimum stress," Precis. Eng., vol. 42, pp. 6-21, 2015.

[11] J. Pinskier, B. Shirinzadeh, L. Clark, Y. Qin, and S. Fatikow, "Design, development and analysis of a haptic-enabled modular flexure-based manipulator," Mechatronics, vol. 40, pp. 156166, 2016.

[12] S. P. Deshmukh, H. Zambare, K. Mate, M. S. Shewale, and Z. Khan, "System identification and PID implementation on double flexural manipulator," in 2015 International Conference on Nascent Technologies in the Engineering Field, ICNTE 2015 Proceedings, 2015.

[13] S. Xiao and Y. Li, "Optimal design, fabrication, and control of an $\mathrm{XY}$ micropositioning stage driven by electromagnetic actuators," IEEE Trans. Ind. Electron., vol. 60, no. 10, pp. 4613-4626, 2013.

[14] J. Qu, W. Chen, J. Zhang, and W. Chen, "A piezo-driven 2-DOF compliant micropositioning stage with remote center of motion," Sensors Actuators, A Phys., vol. 239, pp. 114-126, 2016.

[15] Z. Zhang and H. Hu, "Flexural mechanism design analysis for a new piezoelectric inchworm actuator," in 2009 International Conference on Measuring Technology and Mechatronics Automation, ICMTMA 2009, 2009, vol. 1, pp. 98-101.

[16] E. Du, H. Cui, and Z. Zhu, "Review of nanomanipulators for nanomanufacturing," Int. J. Nanomanuf., vol. 1, no. 1, pp. 83104, 2006

[17] J. Pinskier, B. Shirinzadeh, L. Clark, Y. Qin, and S. Fatikow, "Design, development and analysis of a haptic-enabled modular flexure-based manipulator," Mechatronics, vol. 40, pp. 156166, 2016.

[18] M. Olfatnia, L. Cui, P. Chopra, and S. Awtar, "Large range dual-axis micro-stage driven by electrostatic comb-drive actuators," J. Micromechanics Microengineering, vol. 23, no. 10,2013

[19] J. J. Kim, Y. M. Choi, D. Ahn, B. Hwang, D. G. Gweon, and J. Jeong, "A millimeter-range flexure-based nano-positioning stage using a self-guided displacement amplification mechanism," Mech. Mach. Theory, vol. 50, pp. 109-120, 2012.

[20] J. Pinskier, B. Shirinzadeh, L. Clark, Y. Qin, and S. Fatikow, "Design, development and analysis of a haptic-enabled modular flexure-based manipulator," Mechatronics, vol. 40, pp. 156 166,2016

[21] S. S. Mulik, S. P. Deshmukh, M. S. Shewale, H. B. Zambare, and A. P. Sundare, "Design and implementation of position estimator algorithm on double flexural manipulator," in 2017 International Conference on Nascent Technologies in Engineering, ICNTE 2017 - Proceedings, 2017. 